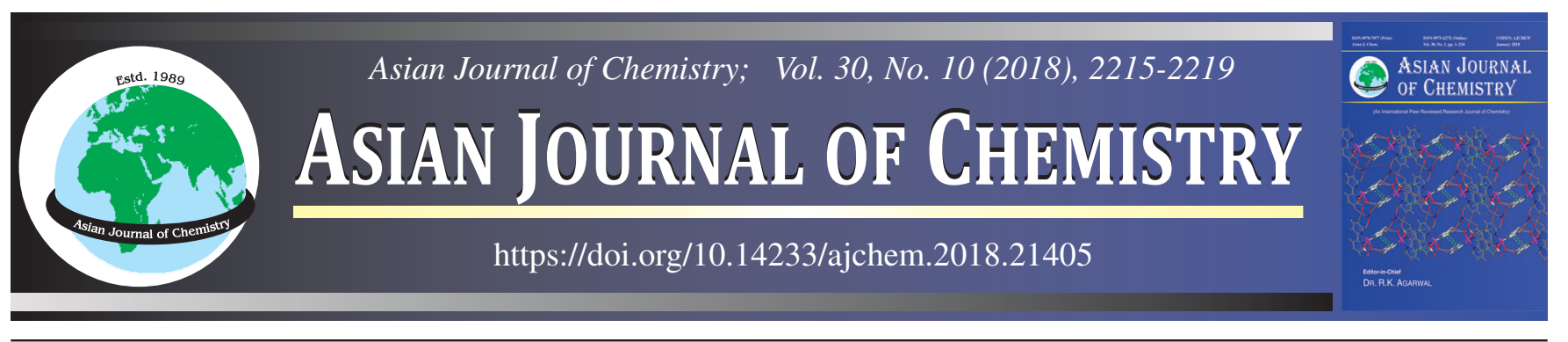

\title{
Isolation and Spectral Characterization of Degradation Impurity in Perampanel Drug Substance Using UPLC-MS and NMR Spectroscopy: Validation of Assay Method by UPLC
}

\author{
Shaik John Saida ${ }^{1,2, *}$, Muniappan Muthuchamy ${ }^{1}$, Muralidharan Kaliyaperumal ${ }^{2}$, \\ Chidananda Swamy Rumalla ${ }^{2}$, Ramulu Yanaka ${ }^{2}$ and S. Venkat Rao ${ }^{3}$
}

${ }^{1}$ Bharath Institute of Higher Education and Research, Selaiyur, Chennai-600 073, India

${ }^{2}$ Department of Medicinal Chemistry, GVK Bioscience Pvt. Ltd., Hyderabad-500 076, India

${ }^{3}$ SMS Pharmaceuticals Ltd., Hyderabad-500 043, India

*Corresponding author: E-mail: saida_sk2005@yahoo.co.in

Received: 26 April 2018;

Accepted: 17 July 2018;

Published online: 31 August 2018;

AJC-19046

A stability indicating reverse phase ultra performance liquid chromatography (UPLC) for perampanel and identification of degradation products of perampanel from forced degradation studies. Perampanel was subjected to stress conditions of acid, aqueous hydrolysis, oxidative, photolytic and thermal stress degradation. The degradation of perampanel was observed under acid hydrolysis, basic hydrolysis and peroxide and it was stable in thermal, photo degradation conditions. Good resolution was observed between drug and its degradation products with the proposed UPLC method was developed by using mobile phase formic acid in water and acetonitrile. The developed UPLC method was validated with respect to specificity, linearity, accuracy, precision, ruggedness and robustness. The linearity of method was performed concentration levels between 20 to $120 \mu \mathrm{g} / \mathrm{mL}$ with correlation coefficient 0.999 . Assay recoveries were found to be 98.2 to $101.6 \%$. The developed UPLC method was found to be useful to determine the regular production of perampanel samples and its stability studies. Two new degradants were formed (1-2). Both acid and base hydrolysis resulted in the same compound $\mathbf{1}$. However, oxidation by peroxide resulted in another new compound $\mathbf{2}$. Both degradation products were completely characterized by HRMS and extensive NMR, spectrometry. Stability indicating validated method by UPLC and its degradation and cartelization studies were not reported elsewhere.

Keywords: Perampanel, Method validation, Degradation products, HRMS, NMR spectroscopy.

ᄂ - - - - - - - - - - - - - - - - - - - - - - - - - - -

\section{INTRODUCTION}

Perampanel is an antiepileptic drug used in addition to other drugs to treat partial seizures and generalized seizures for people [1]. Perampanel chemically known as 2-(2-oxo-1phenyl-5-pyridin-2-yl-1,2-dihydropyridin-3-yl)benzonitrile (Fig. 1). It was approved in 2012 and as of 2018 its optimal role in the treatment of epilepsy relative to other drugs was not clear [2]. Perampanel is the first antiepileptic drug in the class of selective non-competitive antagonist of AMPA receptors [3].

Perampanel drug was labeled in a black box warning because it may cause serious psychiatric and behavioural changes and homicidal or suicidal thoughts. Other side effects have included dizziness, somnolence, vertigo, aggression, anger, loss of coordination, blurred vision, irritability and slurred<smiles>N#Cc1ccccc1-c1cc(-c2ccccn2)cn(-c2ccccc2)c1=O</smiles>

Fig. 1. Chemical structure of perampanel (m.f.: $\mathrm{C}_{23} \mathrm{H}_{15} \mathrm{~N}_{3} \mathrm{O}$; m.w.: $349.38 \mathrm{~g} / \mathrm{mol}$ )

speech. Perampanel reduced the effectiveness of levonorgestrel oral contraceptives by about $40 \%$ [1]. Women who may get pregnant should not take it as studies in animals show it may harm a fetus [4]. Perampanel is liable to be abused; high doses produced euphoria responses similar to ketamine. It is designated as a Schedule III controlled drug substance by the drug enforcement authority [1]. As of August 2016 perampanel had

This is an open access journal, and articles are distributed under the terms of the Creative Commons Attribution-NonCommercial 4.0 International (CC BY-NC 4.0) License, which allows others to copy and redistribute the material in any medium or format, remix, transform, and build upon the material, as long as appropriate credit is given and the new creations are licensed under the identical terms. 
been studied and development discontinued in migraine, multiple sclerosis, neuropathic pain and Parkinson's disease [5]. Few HPLC methods were reported in the literature for the analysis of perampanel in pharmaceutical formulation [6].

No UPLC methods were reported in major pharmacopoeias. Based on literature survey no methods were found on stability, degradation, isolation, identification and complete characterization of perampanel. The present drug stability test guide lines $\mathrm{Q} 1 \mathrm{~A}(\mathrm{R} 2)$ issued by international council on harmonization (ICH) suggested that stress study should be carried on a drug to establish its stability characteristics, leading to separation of degradation products and hence supporting the stability of the proposed analytical procedures. It also required that analytical test procedures for stability samples should be fully validated [7-9]. The method was developed and validated as per ICH guidelines and the proposed method was accurate, rapid, specific and reproducible for determination of perampanel in bulk drugs.

\section{EXPERIMENTAL}

The drug perampanel (API) was a gift sample received from SMS pharmaceutical Ltd, India. Solvents and buffers chromatographic grade acetonitrile and formic acid form Merk brand and DMSO- $d_{6}$ with TMS $0.03 \%$ (v/v), $\mathrm{D}_{2} \mathrm{O}$ solvents from Cambridge isotope limited, water used from Milli-Q grade.

Waters make ultra high performance liquid chromatography (UHPLC) connected with PDA detector is used for method development and validation and processed with Empower software. and Gilson make Preparative HPLC with liquid handler GX-271, pump module $331 \& 332$ connected with PDA detector, The Waters make HRMS Q-TOF Micro Mass with ion source ESI mode, Capillary voltage: 2800 V; Sample voltage: $30 \mathrm{~V}$; Source temperature: $140^{\circ} \mathrm{C}$ and Leucine encephalin $(\mathrm{m} / \mathrm{z}$ 555.6228) is used internal standard for HRMS analysis and the data was processed with Mass Lynx software. To determine the functional groups by IR spectrum, FT-IR is used from Shimadzu and NMR (400 MHz) instrument is used from Bruker.

Chromatographic and spectroscopic conditions: Degradation impurities were purified by using Gilson prep-HPLC with column Kromasil C18 $(250 \times 20 \mathrm{~mm}) 5 \mu$ with mobile phase A: $0.1 \%$ formic acid in Aquas and B: acetonitrile with gradient elution \% B: $0 / 5,10 / 60,15 / 90,15.5 / 5,20 / 5$ with a flow rate of $20 \mathrm{~mL} / \mathrm{min}$ at room temperature. The crude degradation reaction material was dissolved in mobile phase, filtered and injected $300 \mu \mathrm{L} / \mathrm{inj}$ and purification was monitored at 215 and $290 \mathrm{~nm}$.

${ }^{1} \mathrm{H},{ }^{13} \mathrm{C}$ and $2 \mathrm{D}$ NMR was recorded with $400 \mathrm{MHz}$ NMR instrument and the degradation impurities were recorded in DMSO- $d_{6}$ solvent. Carbon-proton connectivity was confirmed by 2D NMR like COSY, HSQC, HMBC, ${ }^{15}$ NHSQC and ${ }^{15} \mathrm{NHMBC}$ and the hydrogen's attached with hetero atoms were further confirmed by $\mathrm{D}_{2} \mathrm{O}$ exchange experiment.

The waters make Q-TOF micro mass high resolution mass spectrometry (HRMS) is used to find out the accurate mass of the degradation impurities and the data was monitored in positive mode.

For method development water UPLC is used with column Aquity BEH $(100 \times 2.1) \mathrm{mm} 1.7 \mu$ with a buffer combination of buffer A: $0.1 \%$ formic acid in Aquas and \% B: acetonitrile with isocratic elution mode in a ration of 60:40 (A:B), flow: $0.4 \mathrm{~mL} / \mathrm{min}$ at $40{ }^{\circ} \mathrm{C}$. Chromatograms were monitored at 290 $\mathrm{nm}$. The functional group information was done by infrared spectrum in solid state as $\mathrm{KBr}$ medium.

\section{Preparation of solutions}

Stress conditions: The drug was dissolved in $0.5 \mathrm{~N} \mathrm{HCl}$ solution and stirred for $12 \mathrm{~h}$ at $60{ }^{\circ} \mathrm{C}$ and the reaction was monitored by UPLC-MS. For oxidative degradation drug was dissolved in $30 \%$ peroxide solution and refluxed for 2 days at $60{ }^{\circ} \mathrm{C}$ and for base degradation drug was dissolved in $0.5 \mathrm{~N}$ $\mathrm{NaOH}$ and stirred for $16 \mathrm{~h}$ and the degradation was not observed in other stress conditions photo and thermal study.

Purification of degradation compounds: Acid and oxidative degradation crude mixtures were slightly diluted with mobile phase and filtered.

The filtered solution was taken up for the purification by reverse prep-HPLC. Isolated fractions were collected and lyophilized to get fine solid compounds.

Preparation of standard solution: The drug substance $200 \mu \mathrm{g} / \mathrm{mL}$ was transferred in to $100 \mathrm{~mL}$ of volumetric flask and dissolved in $50 \mathrm{~mL}$ of acetonitrile and buffer initially and further make-up to the mark. Stock solution was sonicated for $0.5 \mathrm{~h}$ and filtered. Further dilutions $(20-120 \mu \mathrm{g} / \mathrm{mL})$ were prepared from stock solution to check linearity and system suitability tests.

\section{RESULTS AND DISCUSSION}

Method development and validation of drug substance by UPLC conditions and isolation of its degradation impurities: A new stability indicating method for perampanel and its degradation products was developed. Structures of the degradants were also established. The chromatogram is shown in Fig. 2.

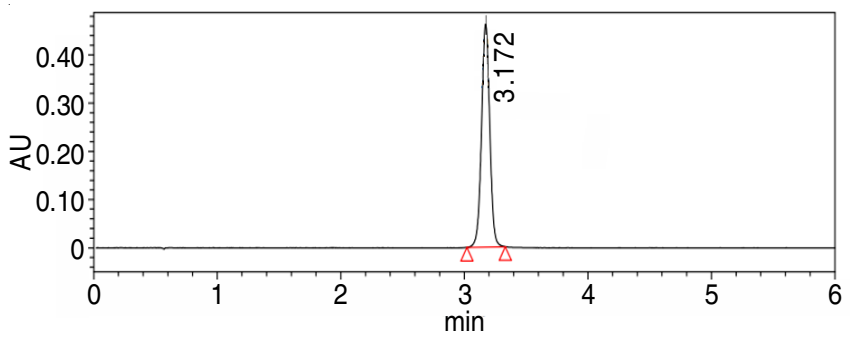

Fig. 2. Chromatogram of perampanel drug

Degradation behaviour of perampanel: Table-1 shows the degradation details of perampanel. Two major impurities were found in acid and oxidative degradation.

In acid degradation $17.02 \%$ of new impurity was found (Fig. 3) and in base degradation almost negligible impurity was observed which is matching with acid impurity. In oxidative degradation $11.68 \%$ of new impurity was found (Fig. 4).

\section{Characterization of degradation products}

Acid degradation product-A: Compared with drug substance ${ }^{1} \mathrm{H}$ NMR of acid degradation product was shown two extra peaks at 7.13 and $7.60 \mathrm{ppm}$ with proton each and it got exchanged in $\mathrm{D}_{2} \mathrm{O}$ exchange experiment. These two protons 


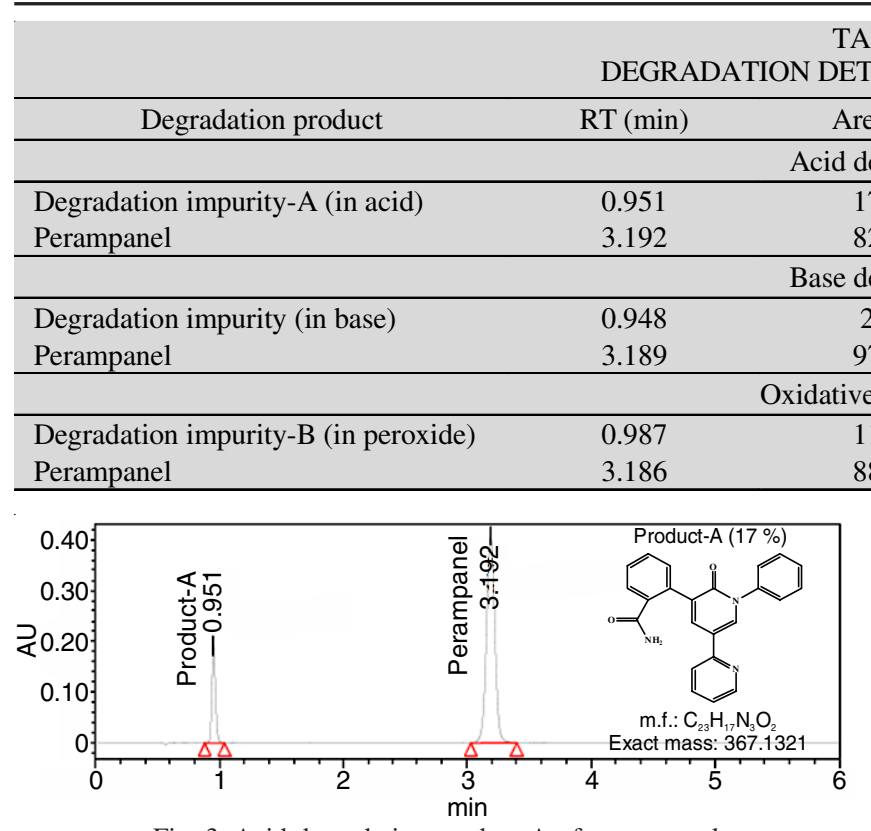

Fig. 3. Acid degradation product-A of perampanel

TABLE-1

ETAILS OF PERAMPANEL

Acid degradation

USP resolution

USP tailing Purity

82.98

25.35

1.14 Pass

1.01 Pass

gradation

97.04

25.86

1.18

1.02

Pass

Pass

11.68

88.32

23.96

1.18

1.02

Pass

Pass

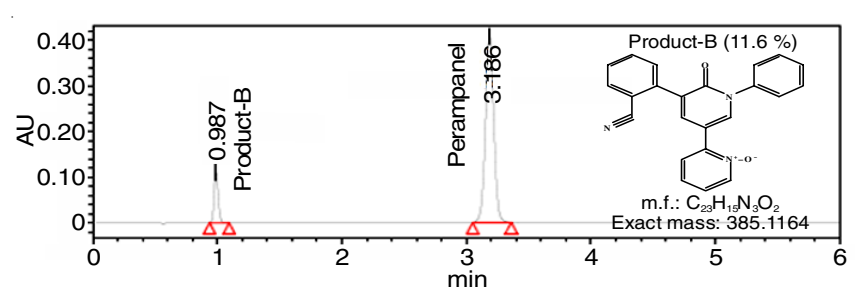

Fig. 4. Oxidative degradation product-B of perampanel

TABLE-2

${ }^{1} \mathrm{H}$ AND ${ }^{13} \mathrm{C}$ NMR ASSIGNMENTS OF ACID AND OXIDATIVE DEGRADATION PRODUCTS A \& B

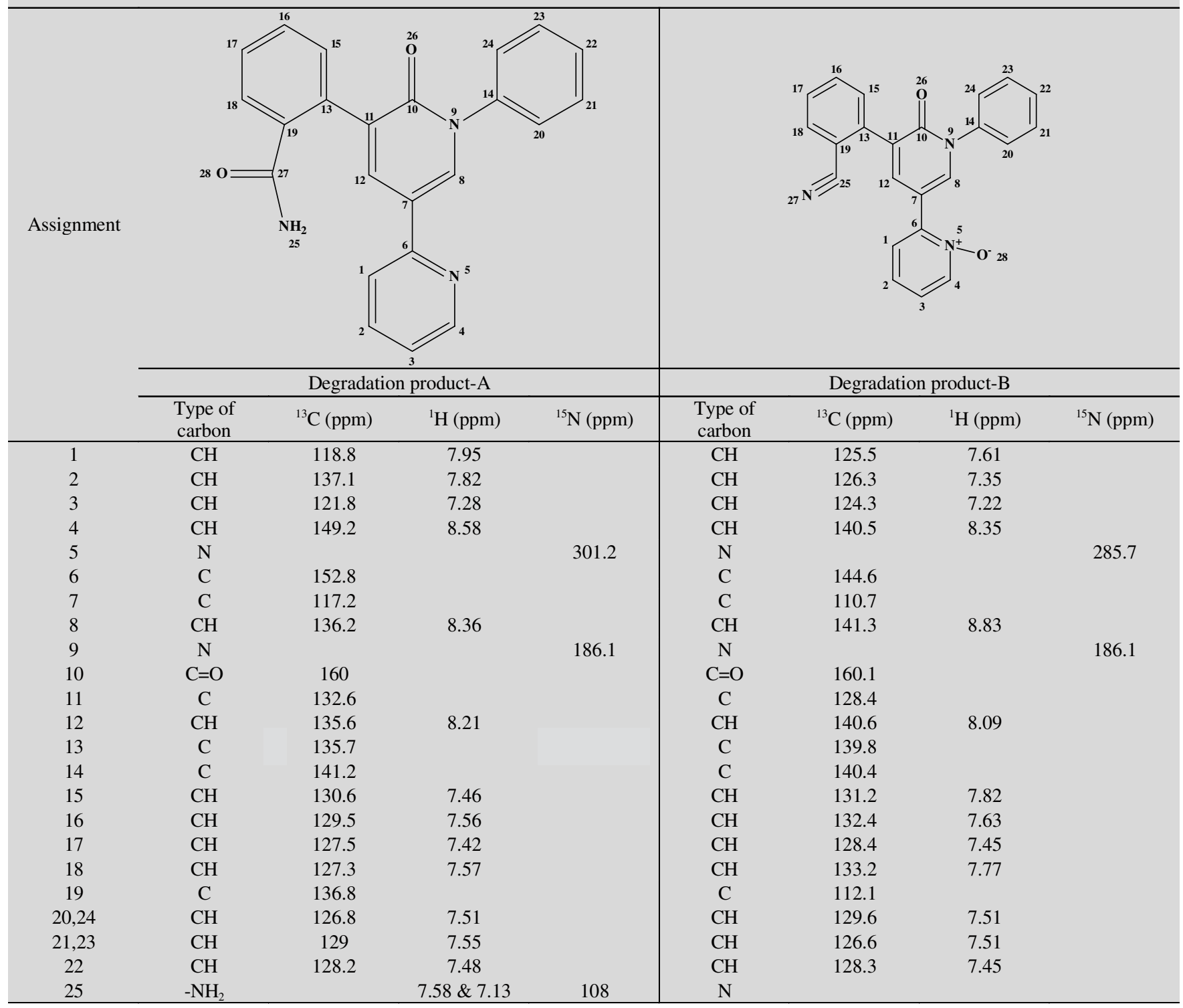


connected with one nitrogen which is confirmed by ${ }^{15} \mathrm{NHSQC}$, its clearly indicated that one extra $-\mathrm{NH}_{2}$ group is present in acid degradation product. Structure was further confirmed by ${ }^{13} \mathrm{C}$ NMR, HSQC, HMBC and ${ }^{15} \mathrm{NHMBC}$.

Carbon-hydrogen connectivity was exactly matching to the acid degradation product-A. For more accuracy results HRMS was performed to know the accurate protonated ion mass $m / z 368.1391$ with chemical formula $\mathrm{C}_{23} \mathrm{H}_{18} \mathrm{~N}_{3} \mathrm{O}_{2}$ with less error $2 \mathrm{ppm}$.

Infrared spectrum was compared with perampanel, observed absence of $-\mathrm{CN}$ at $2217 \mathrm{~cm}^{-1}$ and presence of $-\mathrm{NH}_{2}$ at $3179 \mathrm{~cm}^{-1} \& 3339 \mathrm{~cm}^{-1}$ and other major frequencies are conforms to degradation product-A. Table-2 shows the assignments of ${ }^{1} \mathrm{H}$ and ${ }^{13} \mathrm{C}$ NMR assignments of the degradation product-A.

Oxidative degradation product-B: Number of protons was same for both perampanel and degradation product-B but they differ in their mass. To know accurate mass of this compound was analyzed by HRMS found its molecular protonated ion mass $m / z$ 366.1248, with chemical formula $\mathrm{C}_{23} \mathrm{H}_{16} \mathrm{~N}_{3} \mathrm{O}_{2}$ with less error $1.4 \mathrm{ppm}$ data was confirms to the degradation product-B. Infrared spectrum N-O stretching is observed at $936 \mathrm{~cm}^{-1}$ and $-\mathrm{CN}$ observed at $2217 \mathrm{~cm}^{-1}$ and other major frequencies were conforms to degradation product-B. Protoncarbon connectivity was confirmed by ${ }^{1} \mathrm{H}$ NMR, ${ }^{13} \mathrm{C}$ NMR, HSQC, HMBC and ${ }^{15}$ NHMBC. NMR data was compared with drug substance the pyridine nitrogen value of degradation product was compared with perampanel, pyridine nitrogen in perampanel at $301.2 \mathrm{ppm}$ was missing and appeared at 285.7 $\mathrm{ppm}$, which clearly confirms to $\mathrm{N}$-oxide product and other correlation were confirmed by 2D NMR. Table- 2 shows the ${ }^{1} \mathrm{H}$ and ${ }^{13} \mathrm{C}$ NMR assignments of degradation product- $\mathrm{B}$. The ${ }^{15} \mathrm{NHMBC}$ data of the drug along with the two degradation products is given in Table- 3 .

\begin{tabular}{|c|c|c|c|}
\hline \multicolumn{4}{|c|}{$\begin{array}{c}\text { TABLE-3 } \\
\text { NITROGEN (ppm) VALUES }\end{array}$} \\
\hline & \multicolumn{3}{|c|}{$\begin{array}{l}\text { Nitrogen ppm values } \\
\text { by }{ }^{15} \mathrm{~N} \text { HMBC }\end{array}$} \\
\hline & $\mathrm{N}(5)$ & $\mathrm{N}(9)$ & $\mathrm{NH}_{2}$ \\
\hline Perampanel (pure drug) & 301.2 & 186.1 & - \\
\hline Acid degradation product-A & 303.4 & 182.1 & 107.4 \\
\hline Oxidative degradation product-B & 285.7 & 186.1 & - \\
\hline
\end{tabular}

Method validation: Proposed method was developed as per ICH guidelines, total six duplicate injections were performed to check the precision of proposed method.
Recovery $100.1 \%$ was observed with proposed method which clearly indicates the accuracy of the method. Linearity was performed for concentration levels $20-120 \mu \mathrm{g} / \mathrm{mL}$ and calculated $\mathrm{R}^{2}$ is within the acceptable limits. LOD \& LOQ were found 0.03 and $0.06 \mu \mathrm{g} / \mathrm{mL}$, respectively.

Six duplicate injections was performed to check the precision of proposed method and \% RSD is within the limit. Accuracy and recovery of the method was proved by spiking $10 \%$ of known concentration to the standard concentrations like 80,100 and $120 \%$ and the assay \% is observed 98.2, 100.6 and 101.6, respectively. Solution stability was checked for the drug storage at specific temperature $\left(2-8^{\circ} \mathrm{C}\right)$ for one month, material was stable in solution.

Method robustness was checked by changing few parameters like temp $\pm 5^{\circ} \mathrm{C}, \mathrm{pH} \pm 0.2$ and flow $\pm 0.2 \mathrm{~mL}$, based on the above trials there is no major changes were observed that the method was robust. Method validation parameters were shown in Tables 4-7.

\begin{tabular}{ccc}
\multicolumn{3}{c}{ TABLE-4 } \\
LINEARITY OF PERAMPANEL \\
\hline $\begin{array}{c}\text { Concentration of } \\
\text { drug }(\mu \mathrm{g} / \mathrm{mL})\end{array}$ & Retention time $(\mathrm{min})$ & Peak area \\
\hline 20 & 3.110 & 437665 \\
40 & 3.128 & 869179 \\
60 & 3.135 & 1304423 \\
80 & 3.127 & 1742361 \\
100 & 3.135 & 2152675 \\
120 & 3.124 & 2592093 \\
\hline
\end{tabular}

\begin{tabular}{c|c} 
TABLE-5 \\
METHOD PRECISION OF PERAMPANEL \\
\hline \multicolumn{2}{c}{ Precision results } \\
\hline Inter-day & Intra-day \\
\hline $\begin{array}{c}\text { Area (Mean } \pm \text { standard } \\
\text { deviation), no. of inj. = six }\end{array}$ & $\begin{array}{c}\text { Area (Mean } \pm \text { standard } \\
\text { deviation), no. of inj }=\text { six }\end{array}$ \\
\hline 2214788 \pm 14497 & $21498931 \pm 2883$ \\
\hline
\end{tabular}

\section{Conclusion}

The new advanced UPLC method is suitable to determine perampanel in bulk drugs. Because of short run time this method is very useful in bulk drugs to run many injections during reaction monitoring of perampanel. Proposed method is suitable to calculate low concentration level of LOD (0.03 $\mu \mathrm{g} / \mathrm{mL})$ and LOQ $(0.06 \mu \mathrm{g} / \mathrm{mL})$.

\begin{tabular}{|c|c|c|c|c|c|c|}
\hline \multirow[b]{3}{*}{ S. No. } & \multicolumn{5}{|c|}{$\begin{array}{c}\text { TABLE-6 } \\
\text { RECOVERY STUDIES OF PERAMPANEL WITH KNOWN CONCENTRATION }\end{array}$} & \\
\hline & \multicolumn{2}{|l|}{ Accuracy } & \multicolumn{2}{|l|}{ Accuracy } & \multicolumn{2}{|l|}{ Accuracy } \\
\hline & $80 \%$ & $\begin{array}{l}80 \%+\text { spike } 10 \\
\% \text { of known con. }\end{array}$ & $100 \%$ & $\begin{array}{l}100 \%+\text { spike } 10 \\
\% \text { of known con. }\end{array}$ & $120 \%$ & $\begin{array}{l}120 \%+\text { spike } 10 \\
\% \text { of known con. }\end{array}$ \\
\hline 1 & 1762590 & 1946400 & 2152670 & 2397990 & 2598616 & 2881563 \\
\hline 2 & 1749682 & 1931057 & 2156033 & 2408838 & 2608335 & 2880873 \\
\hline 3 & 1758712 & 1941517 & 2151521 & 2347355 & 2608052 & 2843761 \\
\hline Mean & 1756994.667 & 1939658 & 2153408 & 2384727.667 & 2605001 & 2868732.333 \\
\hline SD & 6623.144369 & 7838.611038 & 2344.78549 & 32817.02205 & 5531.382377 & 21628.56078 \\
\hline$\% \mathrm{RSD}$ & 0.376958707 & 0.404123358 & 0.10888719 & 1.376132902 & 0.212337054 & 0.753941402 \\
\hline Recovery $(\%)$ & \multicolumn{2}{|c|}{98.2} & \multicolumn{2}{|c|}{100.6} & \multicolumn{2}{|c|}{$\begin{array}{c}101.6 \\
\end{array}$} \\
\hline Average $\%$ of recovery & \multicolumn{6}{|c|}{100.1} \\
\hline
\end{tabular}




\begin{tabular}{lc}
\hline \multicolumn{2}{c}{ TABLE-7 } \\
\multicolumn{2}{c}{$\begin{array}{c}\text { REGRESSION OF UPLC PROPOSED } \\
\text { METHOD FOR PERAMPANEL }\end{array}$} \\
\hline Parameters & Proposed UPLC method \\
\hline RT (min) & 3.17 \\
Theoretical plates $(\mathrm{n})$ & 14900 \\
Symmetry (tailing) & 1.1 \\
Linearity concentrations $(\mathrm{ppm})$ & $20-120$ \\
Regression coefficient $\left(\mathrm{R}^{2}\right)$ & 0.999 \\
Limit of detection $(\mathrm{LOD})(\mu \mathrm{g} / \mathrm{mL})$ & 0.03 \\
Limit of quantification $(\mathrm{LOQ})(\mu \mathrm{g} / \mathrm{mL})$ & 0.063 \\
\hline
\end{tabular}

Hence the precision, linearity, repeatability, rapidness, simplicity and economical of UPLC method is having more advantage of other existed HPLC methods.

In acid degradation study the product- $\mathrm{A}$ is formed with mass $m / z, 367.13$ and having chemical formula $\mathrm{C}_{23} \mathrm{H}_{17} \mathrm{~N}_{3} \mathrm{O}_{2}$ and in oxidative degradation product- $\mathrm{B}$ was formed with mass $m / z 365.11$ having chemical formula $\mathrm{C}_{23} \mathrm{H}_{15} \mathrm{~N}_{3} \mathrm{O}_{2}$, both acid and oxidative degradation products $(\mathrm{A} \& \mathrm{~B})$ were new and fully characterized and confirms to the structure.

The method is confirmed its suitability to determine stability indicating method for perampanel in bulk drug industries.

\section{CONFLICT OF INTEREST}

The authors declare that there is no conflict of interests regarding the publication of this article.

\section{REFERENCES}

1. J.E. Frampton, Drugs, 75, 1657 (2015); https://doi.org/10.1007/s40265-015-0465-z.

2. P. Patsalos and F. Besag, Neuropsychiatr. Dis. Treat., 12, 1215 (2016); https://doi.org/10.2147/NDT.S83842.

3. D.J. Chong and A.M. Lerman, Curr. Neurol. Neurosci. Rep., 16, 39 (2016); https://doi.org/10.1007/s11910-016-0640-y.

4. J. Greenwood and J. Valdes, Pharm. Therap., 41, 683 (2014);

5. A.B. Ettinger, A. LoPresti, H. Yang, B. Williams, S. Zhou, R. Fain and A. Laurenza, Epilepsia, 56, 1252 (2015); https://doi.org/10.1111/epi.13054.

6. C.J. Patel, S.S. Patel and M.M. Patel, Int J. Pharm. Drug. Anal., 5, 229 (2017).

7. Stability Testing of New Drug Substances and Drug Products Q1 A (R2), International Conference on Harmonization, IFPMA, Geneva (2003).

8. USP 2011 United States of Pharmacopoeia, United States Pharmacopeia Drug Stability Principles and Practices, edn 34 (2000),

9. M. Bakshi and S. Singh, J. Pharm. Biomed. Anal., 28, 1011 (2002); https://doi.org/10.1016/S0731-7085(02)00047-X. 